\title{
HIGH TEMPERATURE OXIDATION PROPERTY OF SiC COATING LAYER FABRICATED BY AEROSOL DEPOSITION PROCESS
}

\begin{abstract}
This study investigated the high temperature oxidation property of $\mathrm{SiC}$ coated layer fabricated by aerosol deposition process. $\mathrm{SiC}$ coated layer could be successfully manufactured by using pure $\mathrm{SiC}$ powders and aerosol deposition on the $\mathrm{Zr}$ based alloy in an optimal process condition. The thickness of manufactured SiC coated layer was measured about $5 \mu \mathrm{m}$, and coating layer represented high density structure. $\mathrm{SiC}$ coated layer consisted of $\alpha$-SiC and $\beta$-SiC phases, the same as the initial powder. The initial powder was shown to have been crushed to the extent and was deposited in the form of extremely fine particles. To examine the high temperature oxidation properties, oxidized weight gain was obtained for one hour at $1000^{\circ} \mathrm{C}$ by using TGA. The SiC coated layer showed superior oxidation resistance property than that of $\mathrm{Zr}$ alloy (substrate). The high temperature oxidation mechanism of $\mathrm{SiC}$ coated layer on $\mathrm{Zr}$ alloy was suggested. And then, the application of aerosol deposited $\mathrm{SiC}$ coated layer was also discussed.

Keywords: Silicon carbide, Aerosol deposition, Coating, High temperature oxidation
\end{abstract}

\section{Introduction}

Since the Fukushima nuclear power plant explosion incident, the interest in improving the safety of nuclear power plants and nuclear fuel cladding has been increasing. Nuclear fuel claddings must be able to withstand high temperature of $300^{\circ} \mathrm{C}$ and pressure of 200 atmospheres, and must have excellent corrosion resistance and deformation resistance. They also need to have low neutron absorption. Today, $\mathrm{Zr}$ base alloy is commonly used for nuclear fuel cladding. However, $\mathrm{Zr}$ base alloy reacts with $\mathrm{H}_{2} \mathrm{O}$ (used for cooling) when cooling system trouble occurs, and as a result, generates a large amount of hydrogen, which can cause an explosion (like that of the Fukushima power plant).

Therefore, there are demands for nuclear fuel cladding ( $\mathrm{Zr}$ alloy) surface treatment to suppress hydrogen generation and further to prevent explosions. $\mathrm{Cr}_{3} \mathrm{C}_{2}, \mathrm{ZrC}$ and $\mathrm{ZrO}_{2}$ are considered as surface treatment materials, and interest in silicon carbide $(\mathrm{SiC})$ is also increasing. $\mathrm{SiC}$ has outstanding heat resistance, corrosion resistance and wear resistance, and it is known to have high thermal impact resistance due to its low thermal expansion coefficient. In particular, its mechanical properties at high temperatures $\left(1400^{\circ} \mathrm{C}\right)$ are similar to mechanical properties at room temperature. However, $\mathrm{SiC}$ is known to be a difficult material to sinter, and its high hardness and brittleness make it difficult to use as a surface treatment material [1-2]. Plasma spray and chemical vapor deposition (CVD) processes may be used to produce thin film-type $\mathrm{SiC}$. While plasma spray is capable of producing a $\mu \mathrm{m}$ level coating layer using $\mathrm{SiC}$ powder, the heat of the $10,000^{\circ} \mathrm{C}$ plasma melts down most of the $\mathrm{SiC}$, causing decomposition of $\mathrm{Si}$ and $\mathrm{C}$ [3]. In the case of CVD coating process, phase transformation and oxide formation can be avoided, but the extremely slow $1 \mu \mathrm{m} / \mathrm{hr}$ coating makes it inefficient [4].

The aerosol deposition process, which was developed recently, is a process of stacking solid powder (using hundreds $\mathrm{nm}$ to tens of $\mu \mathrm{m}$ powder) without melting. Due to the fact that no melting takes place, materials sensitive to temperature do not cause phase transformation. In addition, by using the pressure difference between the aerosol chamber and deposition chamber, powder can be stacked at a high speed of 100 500 m/s by spraying the powder to collide on the base material. Also, the coating layer has high density and the process is unique as it can be applied on high brittleness materials such as ceramic.

This study attempted to produce a $\mathrm{SiC}$ coated layer using aerosol deposition, which is capable of supplementing the shortcomings of existing procedures, and the study also investigated the high temperature oxidation properties of the $\mathrm{SiC}$ coated layer. Furthermore, this study discussed the possibilities of $\mathrm{SiC}$ coated layer as a high temperature oxidation resistance material.

\footnotetext{
INHA UNIVERSITY, 100 INHA-RO, INCHEON, 22212, KOREA

** KSD KOREA, ANDONG-SI, REPUBLIC OF KOREA

*** KOREA ATOMIC ENERGY RESEARCH INSTITUTE, DAEJEON-SI, REPUBLIC OF KOREA

\# Corresponding author: keeahn@inha.ac.k
} 


\section{Experimental}

The powder used in this study was produced by crushing an ingot made with the Acheson method $\left(3 \mathrm{C}+\mathrm{SiO}_{2} \rightarrow \mathrm{SiC}+2 \mathrm{CO}\right)$. The shape and size distribution of the $\mathrm{SiC}$ powders were shown in Fig. 1. The $\mathrm{SiC}$ powders had an average particle size of $37.4 \mu \mathrm{m}$ and had a polygonal shape. It was first dried at $100^{\circ} \mathrm{C}$ for one hour. Preliminary tests were performed using the dried powder, and the manufacturing conditions were decided based on the results. The base material used for the study was a $\mathrm{Zr}-\mathrm{Nb}$ base alloy. The vacuum level of the deposition chamber was maintained at 300 380 mTorr. He gas flow rate was 5L/min., the distance between the nozzle and the base material was set to $3 \mathrm{~mm}$, and the nozzle speed was set to $2 \mathrm{~mm} / \mathrm{sec}$.

In order to observe the microstructure and to perform phase analysis of the coating layer produced, the specimen was cut in the vertical direction of the stack direction and mounting was conducted. The specimen was polished using SiC paper \#2000 and then, fine polishing was performed up to the diamond paste $(1 \mu \mathrm{m})$ level. The polished specimen was then observed using scanning electron microscope/energy dispersive X-ray spectrometer (SEM/EDS) (Tescan, VEGA II) to verify coating layer formation and measure its thickness. A micro Vickers hardness tester was used to measure the hardness of the coating layer produced. With the condition of $50 \mathrm{~g}$ load applied for 10 seconds, measurements were taken after 30 times, and the average was calculated excluding the minimum and maximum values. X-ray diffraction (XRD, Ultima VI, $\mathrm{Cu}$ target, $\mathrm{Cu} \mathrm{k}_{\alpha}$ radiation) was used to analyze the phases of initial powder and initial coating layer, and the phases after oxidation were also analyzed. Electron probe micro-analyzer (EPMA) (Shimadzu Co., EPMA-1600) analysis was performed to identify the distribution of alloying elements and oxygen elements. An oxidation test was performed using thermal gravimetry analysis (TGA) (Rigaku Co., TG-8120) equipment. The condition used was a $5^{\circ} \mathrm{C} / \mathrm{min}$. heating rate, and the specimen was heated up to $1000^{\circ} \mathrm{C}$ and then the condition was maintained for 1 hour. SEM, XRD and EPMA phase analyses of the oxidized specimens were also performed.

\section{Results and discussion}

Fig. 2(a,b) is a cross section of the $\mathrm{SiC}$ coated layer manufactured by using the aerosol deposition process. As shown in figures, no peeling or cracks were found in the boundary between the $\mathrm{SiC}$ coated layer and base material. The $\mathrm{SiC}$ coated layer thickness measured approximately $5 \mu \mathrm{m}$. There were no macro defects such as pores in the $\mathrm{SiC}$ coated layer, and observation confirmed that the coating layer was highly dense. The initial powder collided with the base material due to large kinetic energy, and the collision resulted in even stacking of the powder without any macro defects. The XRD analysis results (c) identified $\alpha$-SiC as well as $\beta$-SiC in the initial powder, and the as-deposited coating layer featured $\alpha$-SiC and $\beta$-SiC along with $\alpha-\mathrm{Zr}$ and $\mathrm{Nb}$ phases (from base material). This result is a reflection of the advantage of aerosol deposition, which accelerates solid powders without using a heat source, resulting in the maintenance of phases of the initial powder in the coating layer.

Fig. 3 shows the high temperature oxidation results of the $\mathrm{SiC}$ coated layer and $\mathrm{Zr}$ alloy base material. The weight gain of base material increased by approximately $0.25 \%$ after the oxidation, and that of the $\mathrm{SiC}$ coated layer increased by $0.17 \%$ due to oxidation. Furthermore, while the oxidation weight increase curve of the base material increased significantly as time passed, the SiC coated layer featured a relatively lower inclination. Importantly, the oxidation test of coating material in this test used a specimen with a single surface of SiC coating on the base material plate. This allowed the other five surfaces to be oxidized on the base material simultaneously, and the total weight gain increase (including the oxidation of other five base (a)

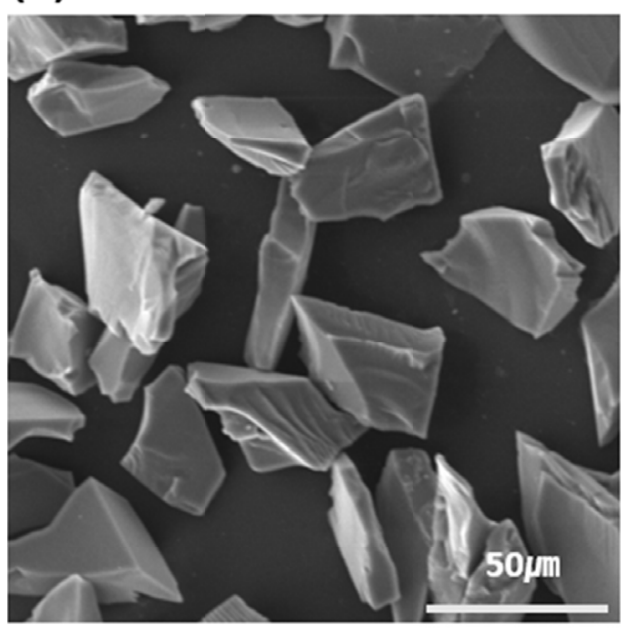

(b)

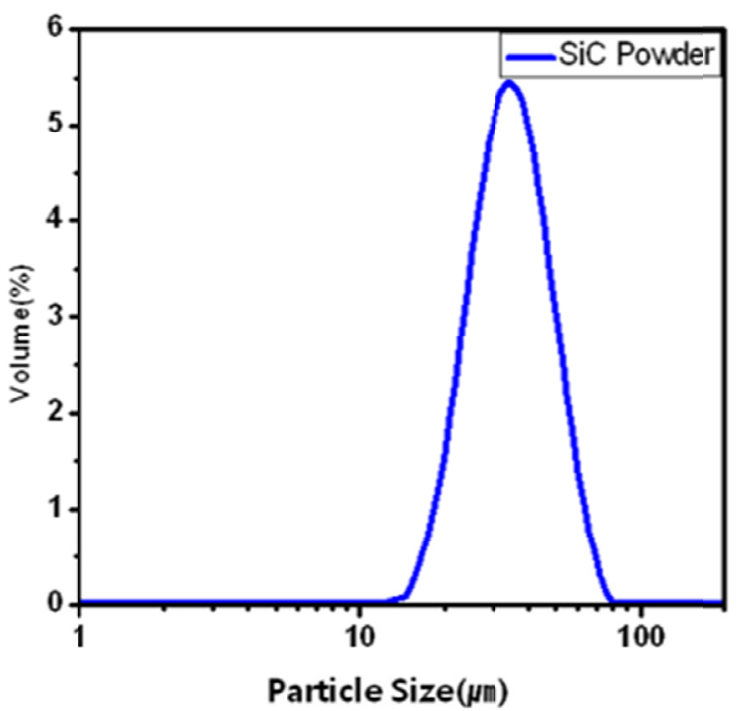

Fig. 1. (a) Shape and (b) particle size distribution of SiC powders 

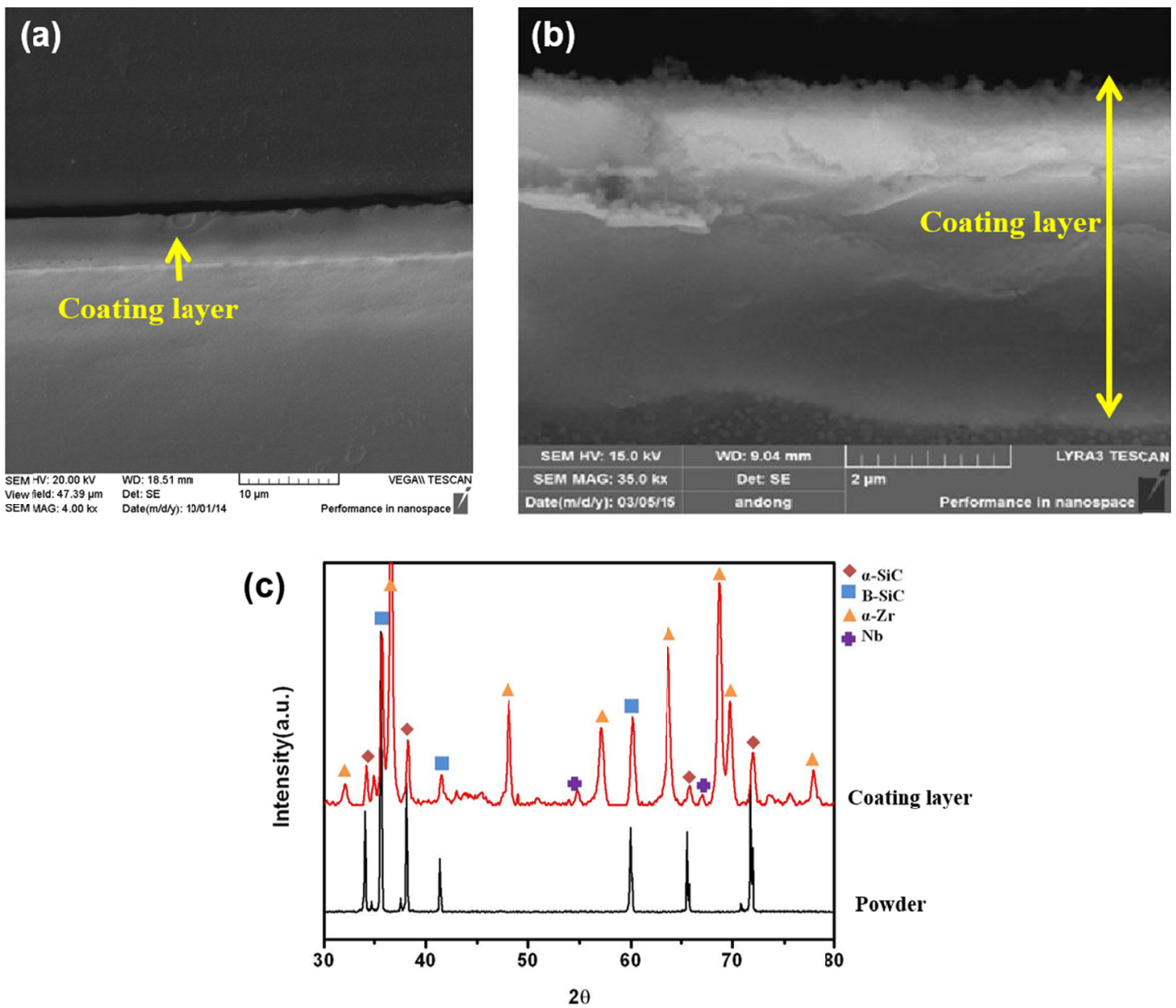

Fig. 2. SEM observation results $(\mathrm{a}, \mathrm{b})$ of $\mathrm{SiC}$ coated layer on $\mathrm{Zr}$ alloy base material and (c) XRD analysis results of $\mathrm{SiC}$ powder and $\mathrm{SiC}$ coated layer on base material

material surfaces) was applied on the oxidation result of the coating material. With such considered, the $\mathrm{SiC}$ coating material has outstanding oxidation resistance compared to the $\mathrm{Zr}$ alloy base material. If a cylindrical nuclear fuel cladding is coated with $\mathrm{SiC}$ using aerosol deposition, it may have significantly lower oxidation weight gain compared to the measurement of this test (outstanding oxidation resistance).

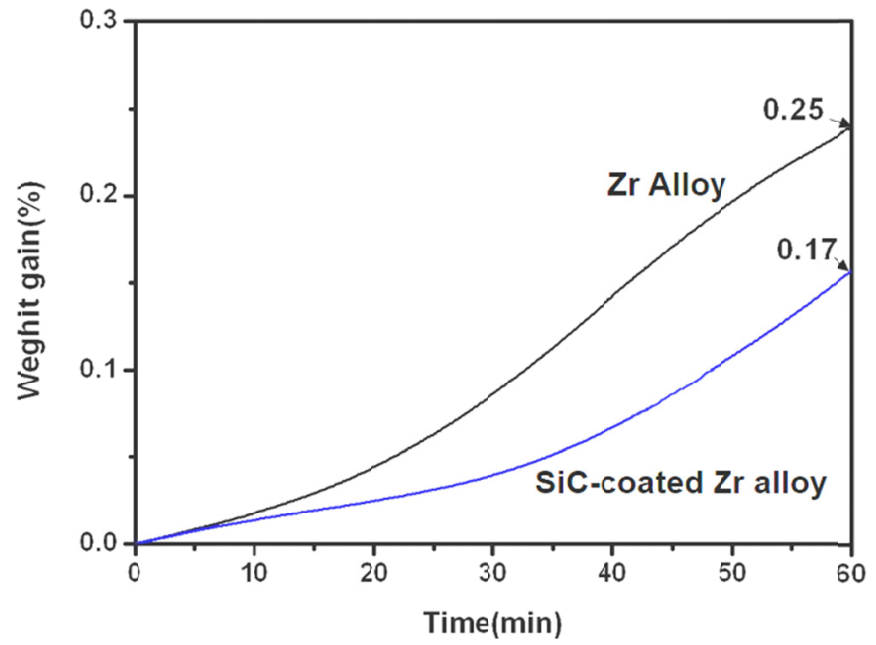

Fig. 3. High temperature oxidation curves (weight gain vs. time) of base material and $\mathrm{SiC}$ coating material
Fig. 4(a) is the XRD analysis results before and after oxidation of the base material, and (b) is the XRD analysis results before and after oxidation of the $\mathrm{SiC}$ coating material. The oxidation layer of $\mathrm{Zr}$ alloy base material featured a mono$\mathrm{ZrO}_{2}$ phase as its main oxide after the oxidation, and a high temperature stable phase, tetra- $\mathrm{ZrO}_{2}$ phase, was also found. The oxidation layer of $\mathrm{SiC}$ coating material featured $\mathrm{SiO}_{2}$, tetra- $\mathrm{ZrO}_{2}$ and mono- $\mathrm{ZrO}_{2}$ after oxidation, in addition to the phases found before oxidation. Considering that the thickness of $\mathrm{SiC}$ coated layer was approximately $5 \mu \mathrm{m}$, the coating layer oxidized as $\mathrm{SiO}_{2}$ and the $\mathrm{XRD}$ results detected oxides (tetra- $\mathrm{ZrO} \mathrm{r}_{2}$ and mono- $\mathrm{ZrO}_{2}$ ) formed on the $\mathrm{Zr}$ alloy base material beneath it.

SEM/EDS was conducted to measure the thickness of the oxidized layer and to perform phase analysis, and the analysis results of the oxidized layer are shown in Fig. 5. The oxidized layer thickness of the base material was approximately $263 \mu \mathrm{m}$, and the oxidized layer thickness of the $\mathrm{SiC}$ coating material was $57 \mu \mathrm{m}$. The oxidized layer of the base material was 4.6 times thicker than that of the $\mathrm{SiC}$ coating material. This is proof that the $\mathrm{SiC}$ coated layer successfully delayed the oxidation of the base material. Meanwhile, close observation of the oxidation layer of base material identified massive cracks and oxidized layer peeling on the surface after the formation of the oxidized layer. The EDS analysis of the oxidation layer of the $\mathrm{SiC}$ coat- 
(a)

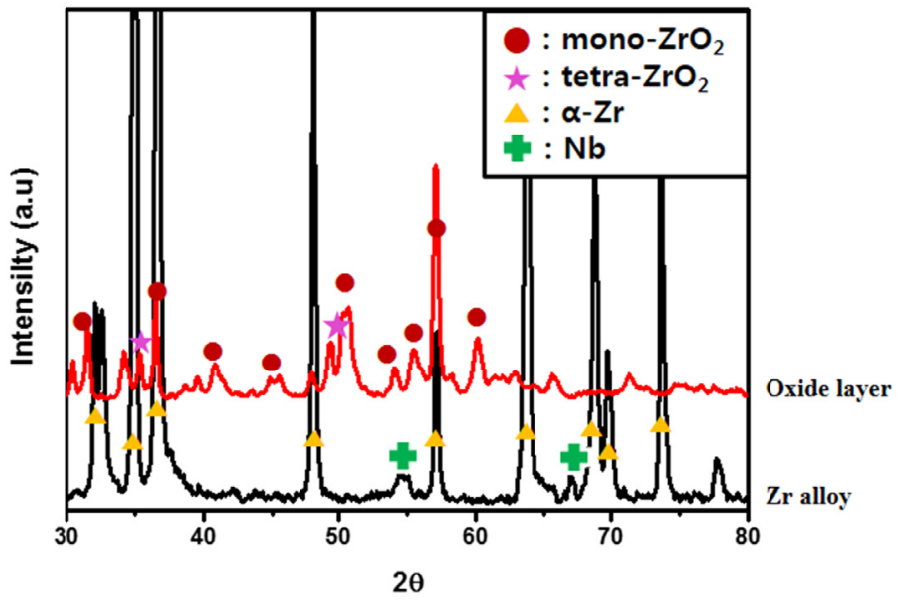

(b)

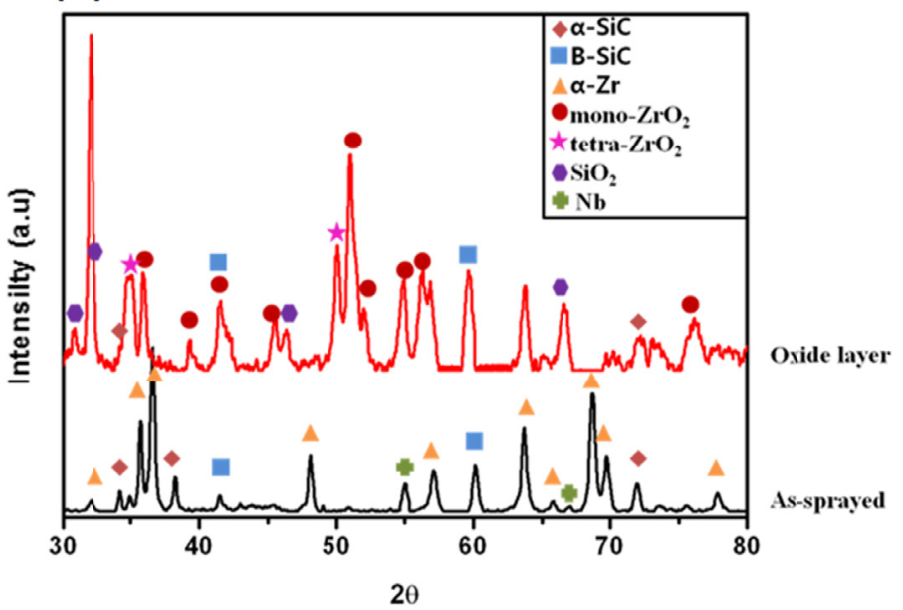

Fig. 4. XRD analysis results of (a) base material and (b) SiC coating material before and after oxidation

ing material identified $\mathrm{Si}$ and $\mathrm{O}$, which are indications of $\mathrm{SiO}_{2}$ phase present in the oxidation layer.

The results of EPMA analysis, which is capable of identifying the element distributions of the oxidation layers, are shown in Fig. 6, and the results were also identical to the results mentioned above (Fig. 4 and Fig. 5). In the case of the oxidation layer of base material, $\mathrm{Zr}$ and $\mathrm{O}$ are in the same location. The oxidation layer thickness of base material, which is measured using the distribution depth of oxygen, was significantly deeper compared to that of $\mathrm{SiC}$ coating material. Some regional cracks also were found in the oxidation layer of base material. In the case of the oxidation layer of $\mathrm{SiC}$ coating material, $\mathrm{O}$ and $\mathrm{Si}$ were detected in the same location. Considering the previously mentioned XRD results (Fig. 4) and SEM/EDS results (Fig. 5), the phase found in the location where $\mathrm{Si}$ and $\mathrm{O}$ were found is assumed to be $\mathrm{SiO}_{2}$. Meanwhile, there were regions where $\mathrm{C}$ and $\mathrm{Si}$ overlapped in the coating layer. This was confirmed to be a case where SiC failed to transform completely into $\mathrm{SiO}_{2}$ and there were partial $\mathrm{SiC}$ in certain areas.
In the case of the oxidation layer of base material, a high temperature stable phase, tetra- $\mathrm{ZrO}_{2}$ phase (known to have outstanding oxidation resistance) was formed, and as oxidation progresses, the tetra- $\mathrm{ZrO}_{2}$ phase is known to transform into a mono- $\mathrm{ZrO}_{2}$ phase [5]. Furthermore, it is widely known that the amount of mono- $\mathrm{ZrO}_{2}$ increases as oxidation progresses, the oxidation resistance of tetra- $\mathrm{ZrO}_{2}$ decreases, fine cracks are formed (Fig. 5) and oxidation progresses rapidly. On the other hand, the oxidation layer of $\mathrm{SiC}$ coating material in Fig. 5 did not form any cracks after oxidation. There were fine cracks formed is some regions of the oxides formed on the base material beneath $\mathrm{SiC}$. $\mathrm{SiO}_{2}$ phase is formed by $\mathrm{SiC}$ reacting to $\mathrm{O}$ in a high temperature atmosphere. $\mathrm{SiO}_{2}$ has outstanding oxidation resistance, which makes it possible to delay further oxidation [6,7]. Based on the results found, the $\mathrm{SiC}$ coating material produced with aerosol deposition stably formed $\mathrm{SiO}_{2}$ in a high temperature oxidation environment, which is capable of effectively suppressing further oxidation of the $\mathrm{Zr}$ alloy base material.
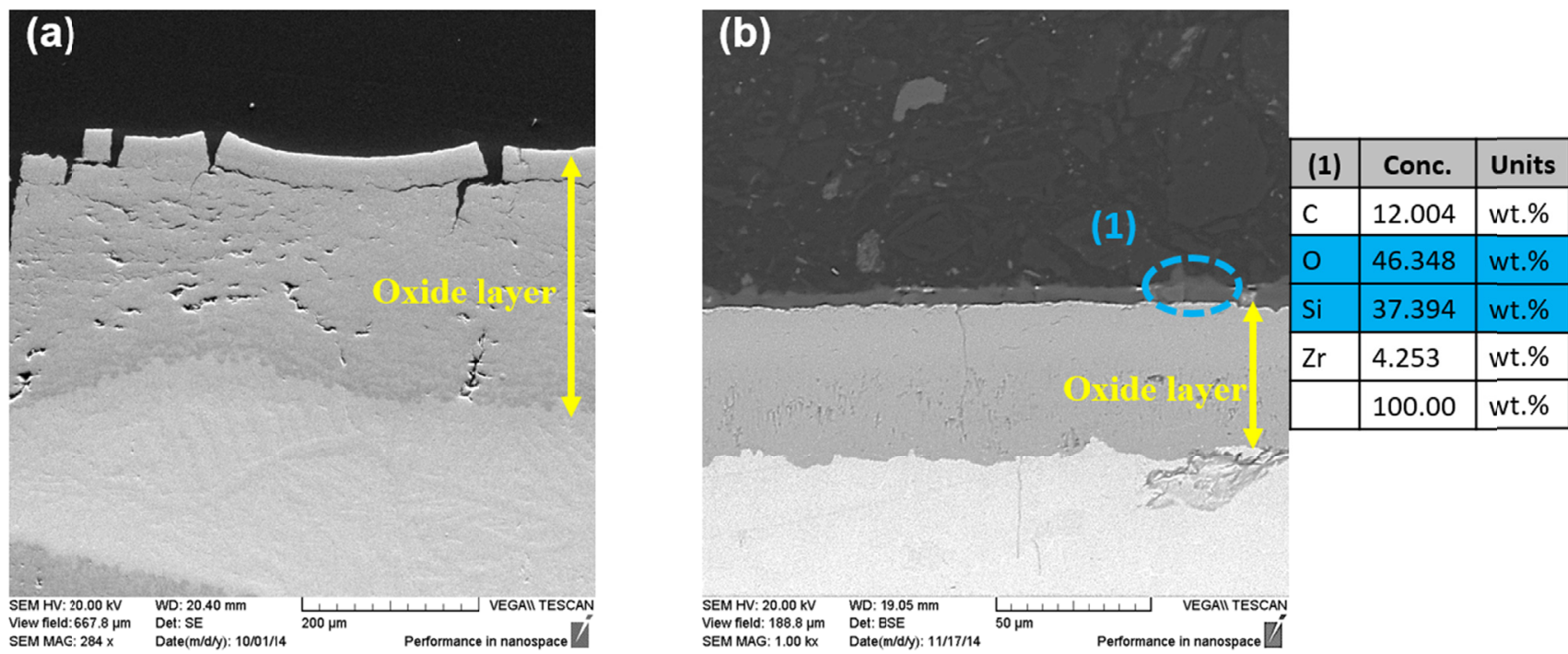

Fig. 5. SEM/EDS analysis results of the oxidation layers of (a) base material and (b) SiC coating material 
(a)
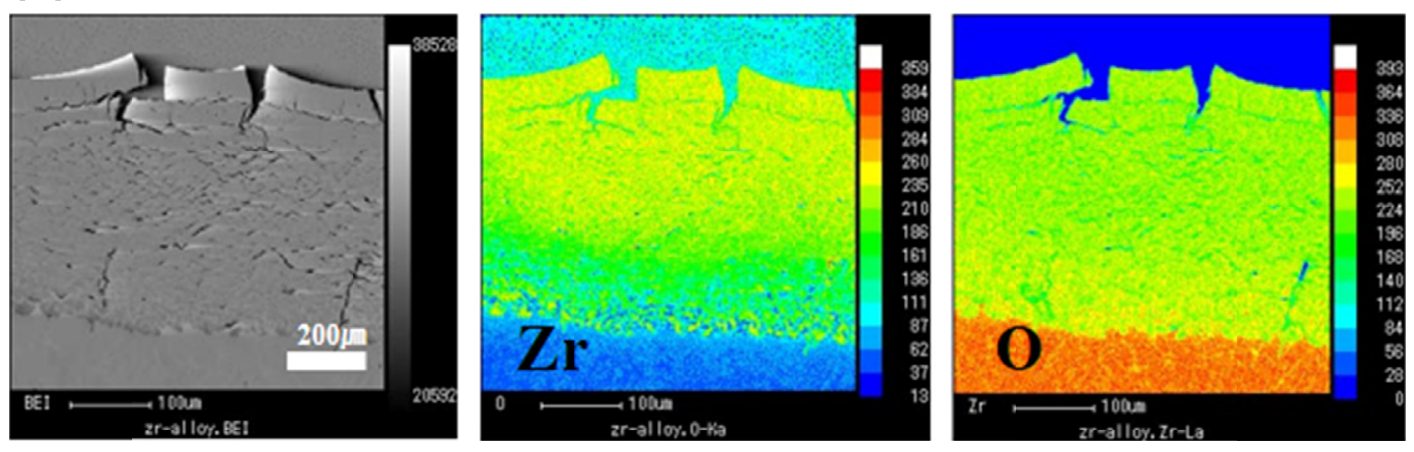

(b)
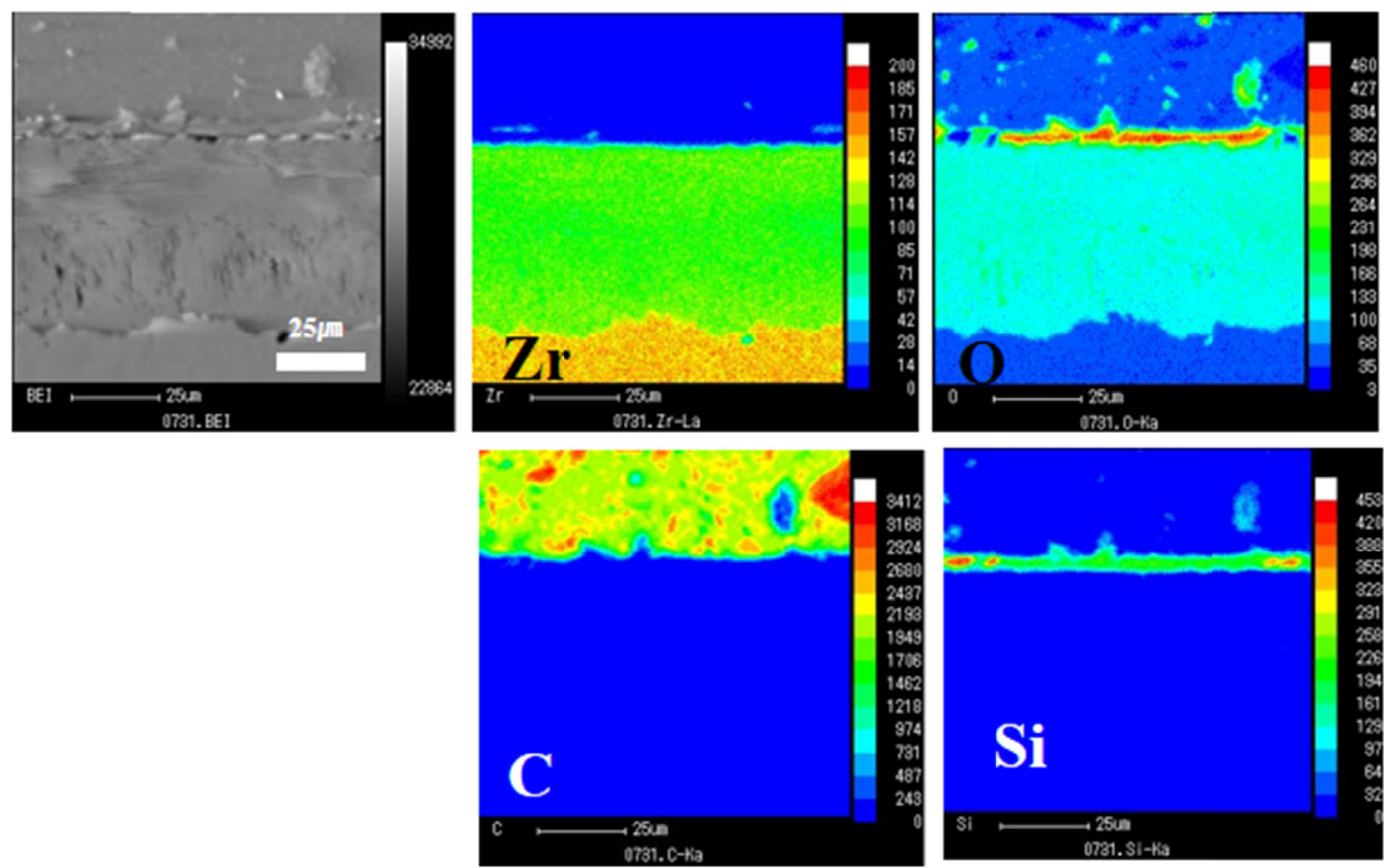

Fig. 6. EPMA analysis results of the oxidation layers of (a) base material and (b) $\mathrm{SiC}$ coating material

\section{Conclusions}

1. A SiC coated layer was successfully manufactured using the aerosol deposition process. The coating layer measured approximately $5 \mu \mathrm{m}$ in thickness, and formed a dense layer without any peeling from the base material. Phase analysis confirmed the presence of $\alpha$-SiC and $\beta$-SiC phases in both the powder and coating layer.

2. The oxidation results confirmed that the $\mathrm{SiC}$ coating material has significantly higher oxidation resistance compared to that of the base material. The oxidation layer on the $\mathrm{Zr}$ alloy base material measured $263 \mu \mathrm{m}$, and $57 \mu \mathrm{m}$ on the $\mathrm{SiC}$ coating material, which makes the oxidation layer of $\mathrm{SiC}$ coating material 4.6 times thinner than that of the base material.

3. The oxidation layer of base material showed massive cracks and peeling on the surface. During high temperature oxidation, stable tetra- $\mathrm{ZrO}_{2}$ phase in the base transformed into the mono- $\mathrm{ZrO}_{2}$ phase, which was thought to lead to a rapid oxidation. $\mathrm{SiC}$ coated layer could contribute to the effective suppression of the oxidation of the base material.

\section{REFERENCES}

[1] A.S. Mukasyan, Y.C Lin, A.S. Rogachev, D.O. Moskovskikh, J. Am. Ceram. Soc. 96, 111 (2013).

[2] K. Choi, J.W. Kim, Korea J. Met. Mater. 50, 569 (2012).

[3] N.F. Fahim, A. Kobayashi, Materials Letters 60, 3838, (2006).

[4] H. Zhang, E.L. Honorato, A. Javed, X. Zhao, J. Tan, P. Xiao, J. Eur. Ceram. Soc. 32, 1775 (2012).

[5] H.G. Kim, Y.H. Jung, T.H. Kim, J. Kor. Inst. Met. \& Mater. 41, 424 (2003).

[6] J. Roy, S. Chandra, S. Das, S. Maitra, Adv. Mater. Sci. 38, 29 (2014).

[7] S.M. Koo, S.J. Yoon, H.S. Kim, J. Korean Powder Metall. Inst. 23, 43 (2016) 